\title{
Establishing Modern Concept of Wealth, Prompting Chinese Social Sustainable Development
}

\author{
Yanping Liu \\ Changchun University of Science and Technology, College of Marxism \\ Changchun 130022, China
}

\begin{abstract}
The concept of wealth is people's fundamental view on wealth and important content of human values, which may deeply influence people's value choices and behaviors. Such problems that the high growth and low development caused after China's opening and reforming, the faster the development is, the more the loss is. And richness causes new poverty at the same time, which actually is closely associated with wrong guidance of traditional concept of wealth. Confronted with the challenges of knowledge economy and the overall requirements of modernization, we must establish comprehensively modern concept of wealth, integrate really tangible material wealth with intangible non-material wealth, attach high importance to the creation of spiritual wealth and cultivate positively wealth quality which contains humanistic bent and social responsibility and thus prompt Chinese social sustainable development truly.
\end{abstract}

Keywords: Concept of wealth, Modernization, Sustainable development

After 1970, the sound of the concept of sustainable development which is based on the sustainable utilization of natural resources and good ecological environment, set economic sustainable development as precondition and pursues the aim of social overall progress is becoming higher and higher in international community. In 1992, Chinese government worked out "Chinese population, resource, environment and development in 21 century white paper" and firstly put sustainable development strategy into the long-term plan of our country's economy and social development. In 1997, the 15th party congress took sustainable development strategy as our country's development strategy positively. In the past thirty years, China's sustainable development was very slow and difficult. Central vigorous propaganda was overwhelmed over local fanatical pursuit of wealth. The party's wise decisions hardly shake people's bias on immediate interests. Therefore, to really realize Chinese social sustainable development, it is not enough to be confined to the propaganda and education of new development view. Only cultivate and establish a kind of modern concept of wealth which keeps pace with times, can we change fundamentally people's perceptions and thus realize scientific development really.

\section{Wealth and its historical changes}

For wealth, there has been too much controversy. Economics tends to interpret it as tangible property or effects; philosophy tends to interpret it as be of great value. In the long human history, the forms of outward manifestation of wealth change great: In agricultural civilization times, land, house and population are wealth people pay the most attention to. The upper part of the character “富” represents house, the middle part “口” represents male labor force, and the under part “田” represents land. Therefore, in agricultural civilization times possesses of the physical substance such as land and house et.al. is to possess of wealth. In industrial civilization times, with the establishment of big machine production mode, such tangible assets as machine, factory, equipments, commodity et.al have gradually become wealth people pursue. Nowadays with the advent of knowledge economy, the manifestation forms of social wealth is turning from tangible assets to non-material intangible assets, slightly to an enterprise's brand, management, corporate culture, public image, innovation ability, integrity level, greatly to a country's educational level, degree of rule by law, administration efficiency, ecological environment, cultural degree et.al., which are gradually becoming intangible wealth with tremendous benefits. "2000 countries wealth report" published by the World Bank in 2005 studied and found, the richer the country is, the lower of the ratio tangible assets covers, the higher of the ratio intangible asset covers. This fully proves that nowadays social wealth is changing from tangible properties such as gold, monetary, physical substances and land to more previous intangible properties. Therefore we must make extensible explanation about the concept of wealth with the times, which is the premise and foundation to establish modern concept of wealth.

\section{The wrong guidance of traditional concept of wealth to China's development}

The concept of wealth is people's fundamental view on wealth including the summation of people's standpoint, viewpoint and attitude towards the source and acquisition of wealth and allocation and usage of wealth. The concept of wealth is important content of values while values is subjects' fundamental view or general viewpoint 
on value based on social life practice and cultural tradition, which embodies ideology such as attitude, norms, aim, ideal et.al that people choose and pursue in real life. Therefore, wealth view may deep influence people's value choice and behavior. Looking back the mistakes appeared in the past thirties years of China's opening and reforming, all without exception are misguided by traditional concept of wealth, which is shown specifically as follows:

1) Traditional concept of wealth leads to China's high growth and low development

Influenced by traditional concept of wealth, now people still see wealth as tangible assets but ignore the creation and accumulation of non-material intangible assets. After opening up and reforming, China's social (material) wealth grows very fast indeed: steel production ranks first in the world, food production ranks first in the world, cement production ranks first in the world, car production and sales rank first in the world...... But in the back of these glorious data, we must face up to the reality of China's social low development. For example, high growth didn't bring to high employment. According to international experience, each percentage point of GDP growth may generate 8 million new jobs. But in China since 1990s, each percentage point of GDP growth has only increased 1200 thousand jobs; in later stage of 1990s the jobs has reduced to 800 thousand. There is variation in China for Okun's Law which is approved abroad. Another example is high output but low profits. China is the manufacturer recognized by the world but actually 60 percent of exports are controlled by foreign companies and most profits are taken by foreign companies. In addition, China's administrative cost ranks first globally; the gap of urban and rural income of China ranks first globally; the tax burden of China ranks second globally; the fairness of China's medical care ranks fourth last globally; China's corruption perceptions index ranks seventy first globally; the death toll from China's coal mining accidents covers 80 percent in the total of the world......From this we can see, after opening up and reforming, the excessive attention and fanatical pursuit of traditional tangible material wealth bring China's dramatic economic growth, but the indifference of intangible wealth such as education, rule by law, services and so on also lead to the severe reality that the overall development level of China society is not high.

2) Traditional concept of wealth leads that the faster China develops, the more the loss is.

After opening up and reforming, China creates a "Chinese miracle" in the world. Its high speed of development has dazzled the world: GDP has increased from 3624 billion in 1978 to 95933 billion in 2001. To calculate at comparable prices, annual growth is $9.4 \%$, which exceeds the world average $3.2 \%$, developed countries' $2.7 \%$ as well as developing countries' $5.2 \%$. China has become one of fastest growing economies in the world. In 2008 after global financial crisis China is recognized as the most dynamic country globally and new engine for world economic recovery. But in the back of proud praise, China also has paid dearly cost for the fast development. For example, in 2006, China accounted for 5. 5\% of global GDP, but accounted for $15 \%$ of total coal consumption, $30 \%$ of steel consumption and $54 \%$ of concrete consumption. According to the reports from academy of sciences, to sort 59 main countries' resource performance in the world, China ranks sixth last. In addition, different places compare unrealistically and construct repeatedly, bringing about real overcapacity. For example, for 600 kinds of main consumer goods which are closely related to people's life nowadays, in fact there is an oversupply of 73.3\% of them. Overcapacity not only leads to large amount of waste of resources, but leads that the massive funds piled up in many enterprises so that enterprises operate badly even loss or bankrupt. There is no doubt that, after opening up and reforming, Chinese social get-rich-quick accords with national people's expectations and interests, but the abnormal pursuit of tangible material wealth and the neglect on such intangible wealth as natural resource and ecological environment have lead that China's development sink into a strange circle: the faster the development is, the more the loss is. Narrow concept of wealth helps people to frenzies looting nature on the way that kill not the goose that lays the golden eggs, almost cutting off the path to sustainable development of China society.

3) Traditional concept of wealth lead that China society richness meanwhile causes new poverty

After opening up and reforming, Chinese people broke mental taboos that "Not fearing deficiency but inequality" in traditional society and early period of the foundation of China and encouraged boldly a part of people and regions to enrich firstly, which is a great achievement indeed. But looking back the thirty years, we have carried out a series of bold reforms in systems, but in the aspect of people's ideology especially the concept of wealth, the reform still lag behind. Nowadays many people especially a lot of rich people's understandings of wealth are still limited to tangible material wealth especially commodity and currency. In recent years, "showing off their wealth" has become a popular lifestyle of many rich people. From a belt with several thousand yuan to a huge meal with 360 thousand yuan, from luxuries show with rising level to purchase of private airplane, Chinese rich people almost show off their wealth with unconventional consumption. If super-rich spend billions of dollars 
extremely luxuriously shows they don't care money, we have rarely seen the rich people would like to pay for China's education, technology, art and culture. According to the reports of China News in September 2010, Bill Gates and Buffett will hold a charity evening party in China but many Chinese rich people refuse to attend it because of worrying about being persuaded to contribute their wealth. Therefore, compared to foreign rich people who are keen on public welfare undertakings, some domestic rich people still lack of real wealth quality. They have not realized that wealth not only means monetized material wealth, but include spiritual cultural wealth filled with humanity and social responsibility. They use wealth for luxurious enjoyment and squander, which is not only low level form to depose their wealth, but exposes their shortcoming in spiritual wealth. We often hear that people comment on a rich person: he is so poor that he has money only. This fully reflects that narrow and backward wealth view has lead people to new poverty while they become rich--the poverty of spiritual value pursuit and morality. From the viewpoint of human all-round development, the abundance of material wealth is the foundation of human all-round development while abundance and comprehension of spiritual wealth is the key to realize human all-round development really. Without the support of spiritual wealth and sinking in greedy pursuit and profligacy of material wealth, people will cause self-alienation in the face of unholy image again, and deviate from the aim of human all-round development and thus make the entire social development deviate from correct pathway.

\section{Cultivate modern concept of wealth positively, promote sound and fast Chinese social development}

The severe social reality shows that, to promote Chinese social healthy and sustainable development, we not only need to plan and design China's social development reasonably from the policy and system levels, but need deep reform in values level. After opening up and reforming, China entered a comprehensive transition period, but many people understand transition as from close to open and from agricultural civilization to industrial civilization, ignoring that in the process from tradition to modern, the modernization of values is the key and fundamental testing criterion to realize modernization comprehensively. Wealth view is import part of values. In goods economy society that economy has permeated into each aspect of social life comprehensively, the role of wealth view in values becomes more important than any other times. In other words, only healthy scientific wealth view can lead human society to go ahead smoothly in the journey of modernization. Therefore, to realize Chinese social modernization really, we must firstly cultivate and establish a kind of modern concept of wealth. Confronted with the detours in the past thirty years under the influence of traditional wealth view, modern concept of wealth should be:

1) On the understanding of the scope of wealth, integrate tangible material wealth with intangible non-material wealth

In the past why we always constructed repeatedly which caused overcapacity is we thought narrowly only such physical material wealth as steel, car was unique wealth, but cannot see the industries had become sunset industries which were transferred and moved in western developed countries because of the advent of knowledge economy. Why there was always high output as well as low profits was we thought narrowly only textiles, toys for children, articles for daily life which marked "made in China" and exports for foreign exchanges are real wealth, but cannot see such non-material wealth as independently design, brand and overall intellectual property in the back of these products are the most important parts of their value and profits. Why there was always extensive growth for us and resource performance ranked sixth last was we only see such tangible material wealth as GDP, enterprises' profits and personal income before our eyes but cannot see the value of such intangible non-material wealth as ecology and environment is larger. In a word, because we lack of a kind of modern concept of wealth that cannot integrate tangible material wealth with intangible non-material wealth really, we emphasize property but ignore intellectual property; we emphasize hardware but ignore software; we emphasize production but ignore brand; we emphasize resource exploitation but ignore technology development; we emphasize introduction but ignore digestion; we emphasize blue collar but ignore white collar and we emphasize hard power but ignore soft power, which leads that we always fall into that paradox that there is growth but no development. Therefore, if China's society go ahead along with the way of sustainable development, we must establish a kind of sound wealth view which integrates tangible material wealth with intangible non-material wealth.

2) On understandings of the level of wealth, attach importance to the creation of intangible spiritual wealth

"2000 countries wealth report" published by the World Bank in 2005 studied and found, not only intangible assets has very high value but they mainly depend on rules by law and education level. Confronted with China's GDP rank in the world, nobody doubts China is a big economy, but they dare not to entitle themselves world power, because we know there is still a gap between China and developed countries in the aspects of social 
fairness, democratic nomocracy, education for all and technological innovation et.al. Therefore, to realize China's modernization comprehensively, on understandings of the level of wealth, we cannot stop in the creation of tangible material wealth but must attach importance to the creation of intangible spiritual wealth. While realizing economic modernization we try to pursue for political modernization, cultural modernization and social development modernization, explore and attempt to accelerate China's legality course overall, prompt Chinese people's education, make efforts to solve the problem of social fairness, resolve all kinds of conflicts in society positively, punish all kinds of corruption severely and establish a nationwide social security system. Only to do that we avoid the performance of tragedy "Latin America trap" so as to prompt China to develop smoothly and successfully, well and fast on the way of modernization.

3) On understandings of essence of wealth, cultivate wealth quality filled with humanity and social responsibility

Influenced by Christian especially Protestant ethic, western people believe commonly wealth is social and that they try their best to obtain wealth is just a way they show their belief to the God. Trying their best to assist other unfortunate brothers in society after obtaining wealth is also to realize the will of God. Therefore, western people are often willing to contribute to society after they become rich, and they think both spending wealth and gathering wealth requires wisdom. Gone in the tycoon is not only the reflection of lack of wisdom, but live up to the God's expectations. It is a kind of disgrace. This kind of modern concept of wealth filled with humanity and social responsibility has become moral view that prompt modern western social to develop well. Although China has no Christian traditions, when establishing commodity economy civilization, we cannot allow the wrong ideology such as "putting money above everything else", "money tells", "Life is all beer and skittles" to spread arbitrarily, and also cannot pay the cost of moral decline in exchange for temporary development of material civilization. In the process of modernization, we must infuse moral soul filled with humanity and social responsibility into people's wealth view, in order to help people to change from the slave of wealth to its real master, so as to avoid human lost in the front of wealth and walk out the development paradox that carrying out market economy means moral disproportion.

\section{References}

Jiang, Guishi \& Yao, Daxue. (2005). Globalization and Asian modernization. Beijing: Social Sciences Academic Press.

Ouyang Xiaopin \& Sun Yiquan. (2007). Survey of wealth view and wealth responsibility during the Transitional Period. Journal of Inner Mongolia Agricultural University. 2007(2).

Wu, Xiping. (2006). Chinese rich people need to establish modern concept of wealth. Watch and think. 2006(22).

Zhu, xiangyuan. (2006). Establish modern concept of wealth. Guangming Daily. 2006-4-24, 2006-5-8. 